\title{
Earthquake Engineering Education: The Mexico-Japan Experience
}

C Mendez Galindo $\$<$ carlosmendez@mail.com>, Hokkaido University, Kita 13, Nishi 8, 060-8628, Sapporo, Hokkaido, Japan

More than twenty years ago, Mexico City suffered the most disastrous earthquake in its history. The death toll from the 1985 Earthquake was an estimated 10,000, with a further 30,000 injured and 100,000 left homeless. 416 buildings were destroyed and over 3,000 seriously damaged. After this event, the profound necessity of effective strategies lead to the creation of the Earthquake Disaster Prevention Project, supported by the Japan International Cooperation Agency (JICA). The main goal of this project was to contribute to the safety of the Mexican population, and eventually become an important aid also for Central America and the Caribbean region.

In 1996, the Earthquake Disaster Prevention Project between Japan and Mexico was successfully completed. The most significant symbol of its achievements is the research facility called CENAPRED. The main purpose of this center has been to work as an organization executing investigations, training and disseminating activities. From that time, various research activities regarding the disaster prevention have been carried out, establishing a new follow-up era of cooperation.

Nowadays, the cooperation between Japan and Mexico keeps strengthening and now includes many areas of action. It carries out, promotes and coordinates research activities not only in terms of earthquake protection strategies, but in general for any type of disaster, like volcanoes or landslides. A successful example is the MEXT scholarship program, which provides high level education to students from developing countries. Every year hundreds of foreign students arrive to Japan to carry out graduate studies in different areas, being engineering one of the strongest. 